\title{
Sustained auditory attention ability in children based on the breathing mode
}

\author{
Joel de Braga Junior ${ }^{1}$ \\ https://orcid.org/0000-0001-6500-9581 \\ Ana Paula Blanco-Dutra ${ }^{2}$ \\ https://orcid. org/0000-0002-6495-7480 \\ Maria Madalena Canina Pinheiro² \\ https://orcid.org/0000-0003-1726-9703
}

Universidade Federal de Santa Catarina - UFSC, Curso de Fonoaudiologia, Florianópolis, Santa Catarina, Brasil. Universidade Federal de Santa Catarina UFSC, Departamento de Fonoaudiologia, Florianópolis, Santa Catarina, Brasil.

This project was carried out at the Curso de Fonoaudiologia da Universidade Federal de Santa Catarina - UFSC, Florianópolis, Santa Catarina, Brasil.

Conflict of interests: Nonexistent

\section{(c) (i)}

Received on: December 12, 2019 Accepted on: April 7, 2020

Corresponding address:

Maria Madalena Canina Pinheiro

Rua Roberto Sampaio Gonzaga, s/n,

Trindade

CEP: 88040-970 - Florianópolis,

Santa Catarina, Brasil

E-mail: madacanina@gmail.com

\section{ABSTRACT}

Purpose: to analyze the auditory behavior and the performance in the Sustained Auditory Attention Ability Test (SAAAT) of children with different breathing modes.

Methods: a total of 30 individuals (19 males and 11 females), ranging from seven to 11 years old, participated in the research. They were distributed into nasal-breathers, mouth-breathers, and oronasal-breathers groups. The Scale of Auditory Behaviors (SAB) questionnaire was applied to those responsible for the children, so as to characterize their auditory behavior. In the SAAAT, the following error patterns were analyzed: inattention, decreased vigilance, impulsivity, and total errors. For the inferential analysis, the Mann-Whitney, chi-square, and Kruskal-Wallis statistical tests were used.

Results: the individuals with mouth- and oronasal-breathing modes had more complaints in the SAB questionnaire when compared with nasal-breathers. Regarding the SAAAT, it was found that the age group of seven to eight years was the one that had the worst performance in the test. The groups with oral and oronasal breathing had more errors, with a statistically significant difference between the groups for inattention and total errors.

Conclusion: it can be concluded that individuals with oral and oronasal breathing had more complaints in the auditory behavior and worse performance in the SAAAT, especially for inattention and total errors.

Keywords: Auditory Perception; Mouth Breathing; Hearing; Attention; Hearing Tests 


\section{INTRODUCTION}

An adequate breathing mode brings benefits to health and quality of life, reducing diseases and stress, and helping in sleep. The breathing mode refers to what entrance the individual uses to breathe, which can be done exclusively through the nose (nasal breathing), exclusively through the mouth (mouth breathing), or partly through the nose and partly through the mouth (oronasal breathing) ${ }^{1}$.

The obstruction of air passage through the nose hinders the breathing function to work properly, making the patient breathe through the mouth. This obstruction can be of organic origin, and some possible causes are nasal septum deviation, adenoid and tonsil hyperplasia, allergic and nonallergic rhinitis, inferior turbinate hypertrophy, among others. Allergic rhinitis is one of the most often causes of alteration in breathing mode ${ }^{2}$.

There are cases in which the individuals present mouth breathing due to a bad habit, instead of mechanical obstruction. These are called habitual breathing, which can be associated with inadequate oral habits, colds, inadequately solved organic factors, flaccid facial and masticatory muscles, and/or genetic factors ${ }^{3}$.

Both functional and habitual mouth breathing alters the patient's posture and behavior - e.g., it can cause learning difficulties or lack of attention. Moreover, mouth breathing for six months or longer can cause facial alterations ${ }^{2}$.

Mouth breathing is responsible for most of the sleep-related problems, in which people tend to present aggressive behavior, mood changes, and hyperactivity/ attention deficit-like behavior. Besides, the auditory skills and cognitive functions, as concentration, attention, and memory, can be impaired, bringing about complaints related to inattention in class ${ }^{4,5}$.

Due to mouth breathing, the air is not filtered, warmed, and moisturized - because the mouth does not have such functions -, leading the bronchi to constrict and the lungs to an elastic depression. With a smaller volume of air breathed in, mouth-breathers have their oxygenation decreased and carbon dioxide pressure partially increased in the blood. In other words, individuals with mouth or mixed breathing, the air arrives in the lungs cold, dry, and impure, making gas exchange harder. This deficiency in lung ventilation causes blood hypoxemia, which in turn leads to a diminished cellular basal metabolism ${ }^{6}$.

Researchers investigated possible relations between mouth breathing and the central auditory system based on the analysis of the temporal resolution auditory skills, binaural integration and separation, divided attention, auditory memory, and auditory closure in a group of students with and without breathing alterations. The authors concluded that mouth-breathing children presented an inferior performance in auditory processing skills when compared with normally breathing children?

The assessment of central auditory processing (CAP) is indicated when the individual presents clinical and/or behavioral signs, such as inattention and learning difficulties, which are common to mouthbreathers ${ }^{7}$. The Sustained Auditory Attention Ability Test (SAAAT) has been currently indicated to assess auditory attention ability. Its purpose is to describe the children's auditory behavior, assessing their ability to respond to a specific stimulus; it assesses the auditory vigilance task, whose role is to quantify sustained attention - i.e., the child's ability to keep attentive and concentrated in the task for a long time ${ }^{8}$.

Considering that many altered-breathing children who are in their learning period present complaints related to attention (unrelated to any organic auditory alteration), it is of great importance to study the sustained auditory attention ability. It is believed that this study will help to direct therapy, minimizing the auditory-based alterations in mouth-breathing children. Furthermore, it is expected to scientifically contribute to the CAP studies, as there are few pieces of research in the literature analyzing the performance of mouthand oronasal-breathing children in sustained auditory attention tests.

Hence, this research aimed to analyze and compare the auditory behavior and performance of children with different breathing modes in the Sustained Auditory Attention Ability Test (SAAAT).

\section{METHODS}

This is a quantitative, observational, cross-sectional, and analytical study. The research took place from August 2017 to May 2018 at the audiology service of a teaching clinic.

Those responsible for the minors were initially instructed about the research1s goals; after the explanation, they signed the Informed Consent Form (ICF), authorizing them to participate in this research. The minors signed the assent form, agreeing to participate in the research. The study was submitted to and approved by the Research Ethics Committee of the 
Universidade Federal de Santa Catarina - UFSC, in Brazil, under protocol no. 2.008.562.

The study population was divided into three groups: nasal-breathers (NB), mouth-breathers (MB), and oronasal-breathers (ONB). The NB comprised nasal-breathing children without complaints of central auditory processing disorder (CAPD) and other comorbidities; the MB comprised mouth-breathing children; the ONB comprised oronasal-breathing children.

The study counted with 30 children - 10 in the NB group (six males and four females), 10 in the MB group (six males and four females), and 10 in the ONB group (seven males and three females). Their age ranged from seven to 11 years, and the mean age was 9.23 years. All the children were attending either elementary or middle school.

The selected participants underwent basic audiological assessment. The auditory thresholds were obtained through air-conduction in the 250 to $8000 \mathrm{~Hz}$ sound frequencies. The normality criteria used were the classification proposed by Lloyd and Kaplan ${ }^{9}$, in which the mean of the 500, 1000 and $2000 \mathrm{~Hz}$ frequencies must be lower than or equal to $25 \mathrm{~dB} \mathrm{HL}$. As for the acoustic immittance measures to assess the integrity of the middle ear, the Jerger classification ${ }^{10}$ was used, and the acoustic reflex testing, both ipsi- and contralaterally, in the $500 \mathrm{~Hz}, 1 \mathrm{kHz}, 2 \mathrm{kHz}$, and $4 \mathrm{kHz}$ frequencies, was based on the Gelfand ${ }^{11}$ and Jerger and Jerger ${ }^{12}$ classification.

The inclusion criteria listed for the groups were children from seven to 12 years old, of both genders, speakers of Brazilian Portuguese as their first language, without middle ear pathologies, with auditory thresholds within standards of normality bilaterally.

Children undergoing or who had undergone either formal or informal CAP therapy, with evidence of craniofacial malformation, genetic syndromes, neurological, motor, mental or any other alterations reported by the adults responsible for them, which could hinder the children's understanding or accomplishment of the tasks proposed were excluded from the population.

The following evaluations were conducted to define the speech-language-hearing breathing diagnosis: a) clinical examination of tonus and mobility of the tongue, lips and cheeks; b) mirror test, in which Altmann's millimeter nasal mirror ${ }^{13}$ was placed under the children's nostrils to verify whether there was vapor in the mirror's upper or lower surface due to breathing; and c) sip-ofwater test, in which the patient was asked to hold the water in their mouth for two timed minutes, with the lips closed, without swallowing it.

The individuals were distributed into the groups, according to the breathing mode, as follows: NB comprised individuals without alterations in any of the tests; MB comprised individuals who failed the sip-ofwater test; and ONB comprised individuals who passed the sip-of-water test but presented alterations in the clinical examinations and/or mirror test.

The adults responsible for the selected participants answered the Scale of Auditory Behaviors $(\mathrm{SAB})^{14}$ questionnaire, as well as a brief anamnesis, in which they were inquired about aspects related to the children's learning, information on their sleep, and alterations in their upper respiratory tract. The $S A B$ questionnaire was used to assess whether there were complaints of CAPD. This questionnaire is composed of 12 CAP-related questions, and its score ranges from 12 to 60 points. The normality standard adopted was that of Nunes, Pereira and Carvalho ${ }^{15}$, which considers the typical auditory behavior beginning at 36 points; a score lower than that indicates a situation of risk of CAPD.

All the individuals that answered the SAB questionnaire underwent orofacial motor function assessment, and met the inclusion criteria were distributed into the respective groups for the SAAAT.

The SAAAT consists of characterizing and quantifying the auditory attention performance through the child's ability to listen to auditory stimuli for an extended period and respond only to a target stimulus. It is an auditory vigilance task whose role is to assess sustained attention. The test was conducted in a sound booth, through a notebook attached to an Interacoustic two-channel AC40 audiometer, at the intensity of $50 \mathrm{~dB} \mathrm{SL}$, considering the tritone mean of the auditory thresholds in the 500, 1000 and $2000 \mathrm{~Hz}$ frequencies. The SAAAT was presented binaurally, lasting 11 minutes on average. This test is composed of 21 monosyllable words, which are repeated until completing a list of 100 words; this list is uninterruptedly repeated six times. The test is available at the SAAAT official website (http://www.thaas.fob.usp.br/login.php).

The patient was instructed that they would hear a list of words and that they should raise their hand whenever they heard the word "no". The 21 selected words were: no (target word), foot, yes, flower, goal, train, sea, sun, want, bad, wool, ox, mine, salt, father, gas, going, sky, now, dust, and one 
Before beginning the test, the patient was trained with a recorded sample of 50 uninterrupted monosyllable words; ten of these were "no". After the patient had understood the instruction, the test was started.

In the SAAAT, the following error patterns were analyzed: inattention, impulsivity, decreased vigilance, and total errors. Decreased vigilance represents the number of right hits regarding the target word in the first presentation, minus the number of right hits regarding the target word in the sixth presentation. Inattention was considered when the child did not raise their hand in response to the target word; and impulsivity, when they raised their hand to a word other than "no". The total error score corresponds to the sum of the inattention and the impulsivity figures. The normality standard followed was that of Feniman'.

For the SAAAT analysis, those individuals who were not within normality standards in the total error score or the decreased vigilance were considered altered.

Descriptive statistical data analysis was made through the absolute and relative frequencies obtained for the categorical variables, and the mean, standard deviation, median, minimum, and maximum values obtained for the numeric and ordinal variables.
The nonparametric chi-square and Kruskal-Wallis tests were used for inferential statistical data analysis. The chi-square test was used to verify the association of the NB, MB and ONB groups with the categorical variables (gender, learning, sleep information, upper respiratory tract alterations, $\mathrm{SAB}$, contralateral reflexes, and SAAAT results). The Kruskal-Wallis, in its turn, was used to verify the association of the NB, MB and ONB groups with the numeric variables (age, SAB score, SAAAT score). All the analyses were made through SPSS for Windows, version 13.0. The p-value was considered significant for values lower than $5 \%$ $(p<0.05)$ and was represented by a superscript asterisk ${ }^{(*)}$.

\section{RESULTS}

In the gender-related population analysis, the chi-square test evidenced that, despite the male predominance $(63.33 \%)$, there was no significant difference between the groups $(p=0.366)$.

The group distribution, according to the complaints reported in the anamnesis by those responsible for the children, is presented in Table 1.

Table 1. Complaints reported by parents/guardians in the anamnesis, according to the breathing mode

\begin{tabular}{|c|c|c|c|c|c|c|c|c|c|c|c|c|}
\hline & \multicolumn{4}{|c|}{ Sleep } & \multicolumn{4}{|c|}{ Learning } & \multicolumn{4}{|c|}{ Upper respiratory tract } \\
\hline & \multicolumn{2}{|c|}{ Normal } & \multicolumn{2}{|c|}{ Altered } & \multicolumn{2}{|c|}{ Normal } & \multicolumn{2}{|c|}{ Altered } & \multicolumn{2}{|c|}{ Normal } & \multicolumn{2}{|c|}{ Altered } \\
\hline & $\mathrm{n}$ & $\%$ & $\mathrm{n}$ & $\%$ & $n$ & $\%$ & $\mathbf{n}$ & $\%$ & $n$ & $\%$ & $\mathrm{n}$ & $\%$ \\
\hline NB & 4 & 40 & 6 & 60 & 9 & 90 & 1 & 10 & 4 & 40 & 6 & 60 \\
\hline ONB & 0 & - & 10 & 100 & 2 & 20 & 8 & 80 & 0 & - & 10 & 100 \\
\hline MB & 0 & - & 10 & 100 & 1 & 10 & 9 & 90 & 1 & 10 & 9 & 90 \\
\hline P-value & \multicolumn{4}{|c|}{$0.010^{*}$} & \multicolumn{4}{|c|}{$0.0003^{*}$} & \multicolumn{4}{|c|}{$0.044^{*}$} \\
\hline
\end{tabular}

Chi-square test.

Legend: $\%=$ percentage; $n=$ number of participants; MB = mouth-breathers; ONB = oronasal-breathers; NB = nasal-breathers.

In the analysis of Table 1, a significant difference was verified between breathing mode and the alterations reported by the parents/guardians, regarding sleep, learning and upper respiratory tract.
The comparison of the groups in relation to the $S A B$ questionnaire descriptive analysis is presented in Table 2. 
Table 2. Descriptive analysis of the results obtained in the Scale of Auditory Behaviors questionnaire for the breathing mode of the groups

\begin{tabular}{cccccc}
\hline & Mean & SD & Min & Max & Median \\
\hline NB & 47.90 & 3.38 & 41 & 51 & 49.00 \\
ONB & 33.50 & 10.50 & 20 & 51 & 33.50 \\
MB & 32.20 & 10.14 & 20 & 57 & 31.50 \\
\hline
\end{tabular}

Legend: $\mathrm{MB}=$ mouth-breathers; $\mathrm{ONB}=$ oronasal-breathers; $\mathrm{NB}=$ nasal-breathers; $\mathrm{Min}=$ minimum; $\mathrm{Max}=$ maximum; $\mathrm{SD}=$ standard deviation.

As verified in table 2, in the ONB and MB groups the mean SAB score was lower than that of the NB group.

In the ONB group, five individuals presented alteration in the SAB $(50 \%)$, whereas nine $(90 \%)$ did so in the MB group. The chi-square test showed a significant difference between breathing mode and the SAB score $\left(p=0.001^{*}\right)$.

In the audiological assessment, only the contralateral stapedial acoustic reflexes were analyzed, as the auditory thresholds within normality standards in the pure-tone threshold audiometry was one of the inclusion criteria for all groups. The chi-square test revealed that there was no significant difference between the acoustic reflex results and the breathing mode either in the right $(p=0.186)$ or the left ear $(p=$ 0.153).

Figure 1 shows the distribution of individuals without contralateral stapedial acoustic reflex per acoustic frequency and ear, according to the breathing mode group.

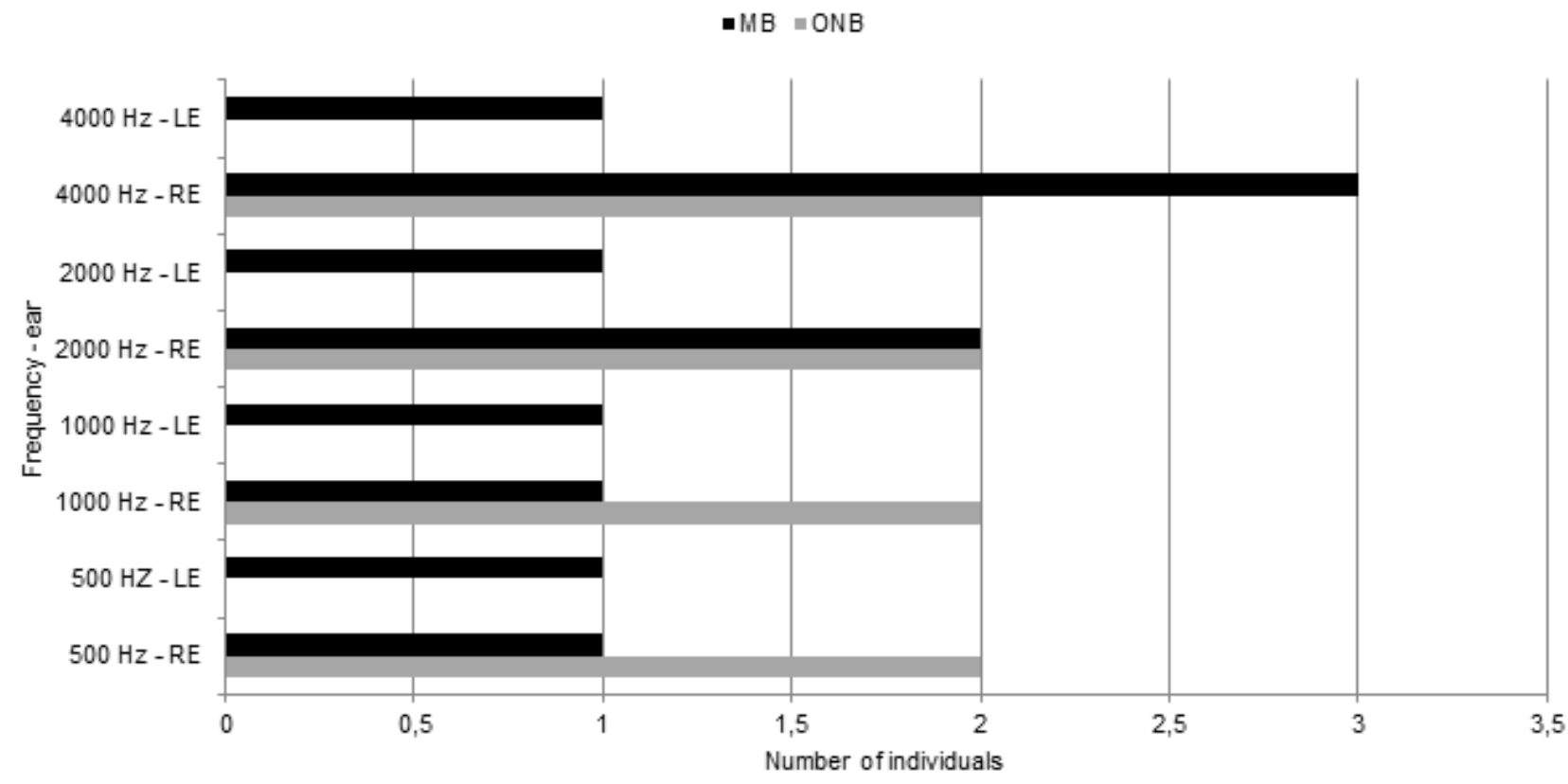

Legend: $\mathrm{MB}=$ mouth-breathers; $\mathrm{ONB}=$ oronasal-breathers; $\mathrm{RE}=$ right ear; $\mathrm{LE}=$ left ear.

Figure 1. Number of individuals with absence of contralateral stapedial acoustic reflex, considering the breathing mode, ear, and frequency 
Concerning the groups, it was verified, in Figure 1, that the MB group was the one that had more absent acoustic frequencies in the contralateral stapedial acoustic reflex.
In Table 3, below, the descriptive statistics of the SAAAT are presented regarding the types of error per age group.

Table 3. Descriptive analysis of the individuals' score in the sustained auditory attention ability test, according to their age

\begin{tabular}{ccccc}
\hline & Inattention & Decreased vigilance & Impulsivity & Total Errors \\
\cline { 2 - 5 } & Mean (SD) & Mean (SD) & Mean (SD) & Mean (SD) \\
\hline 7 years & $29.60(16.47)$ & $5.80(3.27)$ & $2.8(2.58)$ & $32.40(17.85)$ \\
8 years & $27.14(13.74)$ & $4.80(3.28)$ & $6.85(9.11)$ & $33.71(16.90)$ \\
9 years & $28.60(12.97)$ & $3.10(2.23)$ & $2.00(2.10)$ & $30.60(12.88)$ \\
10 years & $16.66(8.57)$ & $3.00(2.75)$ & $3.83(3.31)$ & $20.50(8.71)$ \\
11 years & $7.50(6.36)$ & $1.50(2.12)$ & $1.00(0.00)$ & $8.50(5.865)$ \\
\hline Total & $24.63(13.68)$ & $3.83(2.88)$ & $3.56(5.04)$ & $28.10(14.88)$ \\
\hline
\end{tabular}

Legend: $\mathrm{SD}=$ standard deviation.

In the descriptive analysis of the SAAAT, it was observed that the age groups of seven and nine years were the ones that presented the highest inattention mean values; the seven-year-old group presented the highest decreased vigilance mean values; the eightyear-old individuals presented the highest impulsivity mean values in the test. Regarding the total error score, the age group with the worst performance was the eight-year-old one.

In Table 4, the breathing mode groups are presented, according to their SAAAT performance.

Table 4. Exploratory analysis of the sustained auditory attention ability test, according to the breathing mode

\begin{tabular}{ccccc}
\hline & Inattention & Decreased vigilance & Impulsivity & Total Errors \\
\cline { 2 - 5 } & Mean (SD) & Mean (SD) & Mean (SD) & Mean (SD) \\
\hline NB & $12.80(6.74)$ & $2.40(2.36)$ & $2.90(2.92)$ & $15.50(7.07)$ \\
ONB & $29.10(13.45)$ & $5.00(3.17)$ & $2.50(2.58)$ & $31.00(14.54)$ \\
MB & $32.00(11.79)$ & $4.50(2.75)$ & $4.8(8.01)$ & $39.50(13.07)$ \\
\hline P-value & $0.002^{*}$ & 0.053 & 0.787 & $0.002^{*}$ \\
\hline
\end{tabular}

Kruskal-Wallis test.

Legend: $\mathrm{MB}=$ mouth-breathers; $\mathrm{ONB}=$ oronasal-breathers; $\mathrm{NB}=$ nasal-breathers; $\mathrm{SD}=$ standard deviation.

When analyzing Table 4, it was verified that there was a significant difference between the groups and inattention and SAAAT total score.

Figure 2 presents the types of error most committed by the groups.
Regarding the groups, it was verified, in Figure 2, that the ONB and MB groups had the greatest number of individuals with alterations in the three types of error. 


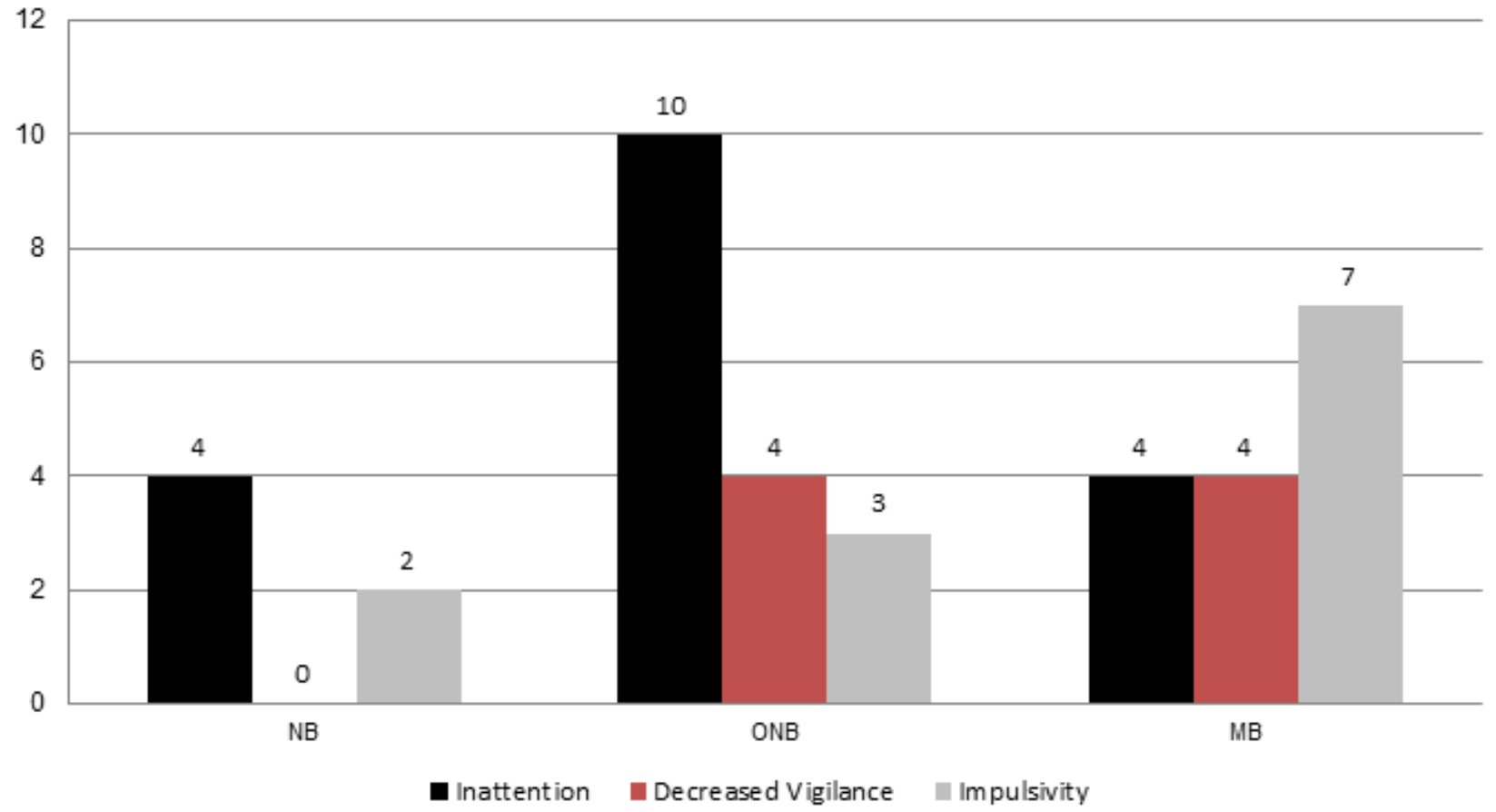

Legend: $\mathrm{MB}=$ mouth-breathers; $\mathrm{ONB}=$ oronasal-breathers; $\mathrm{NB}=$ nasal-breathers.

Figure 2. Frequency of errors most committed by the individuals, according to their breathing mode

\section{DISCUSSION}

The mouth breathing mode is an alteration resulting from the inadequate functioning of the nose, causing breathing function to be fully performed by the mouth. According to the literature, exclusive mouth breathing is rare; more frequent are the cases of individuals with mixed, partly nasal, partly mouth breathing ${ }^{15}$. In this study, both groups had the same number of individuals.

Studies have pointed out that, in the general population, 10 to $25 \%$ present breathing impairment. It is considered a public health issue, which causes loss in people's quality of life, especially in the six- to nine-year-old age group. This confirms the findings of the research whose population's mean age was of nine years, which is the essential age for the development of skills necessary to school learning ${ }^{16}$.

In this study, no significant difference was found between the breathing mode and gender; however, studies demonstrate that mouth breathing is found mainly in males, due to their susceptibility to allergic rhinitis - the main cause of mouth breathing - and narrower airways ${ }^{17}$.

Furthermore, male individuals present more suspicions for CAPD because in the gestation the mother produces high levels of testosterone, which can delay left hemisphere development, causing speech comprehension difficulties, language delays, and academic performance loss ${ }^{18}$.

CPAD manifestations can be found in mouthbreathing individuals, as well ${ }^{7}$; such information can be obtained through questionnaires answered by the adults responsible for the children. Therefore, the information provided in the anamnesis is of utmost importance. Regarding the questions asked to the parents/ guardians (Table 1), it was observed that all groups presented alteration in at least one of the aspects analyzed; the ONB and MB had more complaints when compared with the NB. Of the groups, the most frequent information was related to sleep, followed by upper respiratory tract alterations and, lastly, learning difficulties. These findings corroborate a study that demonstrates that individuals with altered breathing mode have learning difficulties, and sleep-related complaints, besides being more prone to infections in the upper respiratory tract $^{19}$.

Moreover, another study with 1,011 nine- to 14-year-old students proves that individuals with sleep disorders have as their main complaints mouth breathing (both in the day and at night), daytime sleepiness associated with school difficulties, and allergic rhinitis as main upper respiratory tract alteration ${ }^{20}$.

Research conducted to identify six- to nine-year-old mouth breathing children of a public school showed 
that, of the 496 individuals that participated in the research, $56.80 \%$ were mouth-breathers. Most of those responsible for the children reported snoring, openmouth posture, restless sleep, tiredness, and lack of concentration ${ }^{21}$.

In a study evaluating the impairment of cognitivelinguistic skill performance caused by mouth breathing in nine- to 10-year-old children showed that it is possible to observe a large number of individuals with rhinitis, colds, and earaches. However, when each manifestation was analyzed with the cognitive-linguistic skills, no significant differences were observed, demonstrating that the respiratory alterations may not individually impair these skills, though they could do so collectively ${ }^{22}$.

Studies point out that in clinical practice, regardless of the population receiving care, children with behaviorrelated complaints - e.g., distraction, inattention, and school performance difficulties -, involving the mechanisms necessary for speech, reading, and writing, are increasingly common. Such difficulties have repercussions in language and auditory skills development ${ }^{23}$. These studies confirm the importance of referring individuals with breathing alterations for auditory skills evaluation, to prevent future alterations in the learning process.

Research with individuals with sleep apnea showed a neurobehavioral deficit, affecting memory, learning and intellectual ability. The authors associate the hypoxemia with repeated apnea events throughout months or years, which can cause cortical alteration with concomitant dysfunction - from which the person may or may not recover through adequate treatment ${ }^{24}$.

Blunden et al. found in their study a deficit in attention capacity and a decrease in memory and learning scores. The deficit in attention capacity can justify the alteration in intelligence and memory, as it hinders information decoding, storage, learning, and retrieval, leading to consequences in the adult life ${ }^{25}$.

The other study, in its turn, revealed an association between the cognitive deficits and sleep defragmentation associated with hypoxemia episodes and breathing-related awakenings. Moreover, when oxygen saturation decreases more than $3 \%$ during sleep, the person's performance in global intelligence, memory, selective attention, and sustained attention is decreased, which is explained by the late maturation of the prefrontal cortex in relation to other brain structures, thus making it more vulnerable to deleterious physiological effects of hypoxemia ${ }^{26}$.
The SAB questionnaire has been used to complement the CAP assessment. It simply and quickly measures the auditory functioning and is an instrument through which it is possible to infer whether the individual has CAPD-related difficulties ${ }^{27}$.

Concerning the $S A B$ questionnaire, there was a significant difference between the answers given by the parents/guardians in the three breathing mode groups. The ONB and MB groups (whose low mean is suggestive of CAPD) had lower performance than the NB group (Table 2) - i.e., individuals with altered breathing mode can manifest CAPD. These findings suggest that using the relative's information is essential to diagnostic analysis since through the questionnaire it is possible to obtain information on the person's daily life situation, relating it to auditory processing. It must be highlighted, though, that questionnaire does not work as CAPD diagnostic instrument, but a screening one $^{10}$.

Nonetheless, a study aiming to analyze the performance of six- to 12-year-old children diagnosed with obstructive sleep apnea syndrome (OSAS) in temporal resolution abilities showed no significant difference between the SAOS individuals and the SAB questionnaire. This is due to the SAB's apparently being more influenced by the figure-ground and closure abilities than the temporal resolution ones ${ }^{28}$.

However, studies demonstrate that using qualitative questionnaires along with behavioral tests prove them to be correlated, thus aiding in the patient's diagnosis ${ }^{29}$. Hence, it is essential to use questionnaires, given that they are simple and cheap instruments that help to screen children with risk of CAPD, especially in the population studied, who has behavioral manifestations similar to those of CAPD. This makes the use of questionnaires and evaluations viable to early detect individuals who may have CAPD ${ }^{30,31}$.

When analyzing the contralateral stapedial acoustic reflex in the breathing mode groups of children, the MB group presented the greatest number of individuals with the absence of acoustic reflex, highlighting the $4000 \mathrm{~Hz}$ frequency (Figure 1), corroborating the findings of research in which the individuals with suspicion for CAPD present absence of acoustic reflex in $4000 \mathrm{~Hz}$ frequency. This is due to the action of the superior olivary complex in regulating the contraction of the intratympanic muscles and the CAP abilities ${ }^{32,33}$. This shows the importance of referring patients with the absence of contralateral acoustic reflex for complete CAP assessment to early identify possible alterations. 
Therefore, SAAAT can be used to assess these individuals. This test is still being studied and it has the role of assessing sustained auditory attention, helping to determine whether an existing attention difficulty is a factor that collaborates with their failure in learning. It is a simple and easily performed behavioral test, indicated for six- to 11-year-old children, and it can be used in the doctor's office or screenings, so individuals who need specialized evaluation or treatment can be detected ${ }^{34}$.

Furthermore, the test was suggested by the Brazilian Audiology Association (ABA) Forum as complementary in the minimal CAP battery of tests, for the results referring to the patient's sustained attention can contribute to the CAP findings ${ }^{35}$.

Observing the SAAAT results (Table 3), it was observed that the seven-year-old individuals presented more inattention errors (29.60 points) than the 11-year-old ones (7.50 points). This agrees with the literature in that inattention score is inversely proportional to age, reinforcing the study that demonstrates that younger individuals have worse performance in relation to older ones, due to their limited attention capacity - as maturation occurs, inner processes increase such capacity ${ }^{8}$.

Moreover, the studies show that this loss in information is due to the difficulty in keeping attention. Hence, because of inattention, these individuals need to recover the information they had lost, spending more time in schoolwork ${ }^{7,34,36}$.

Regarding the decrease in vigilance, it was observed that the seven-year-old individuals, for being inattentive, ended up presenting higher decreased vigilance mean values when compared with the older individuals - i.e., reduced attention takes place in a certain time, making younger individuals lose focus on activities they are not interested in. This reinforces studies that demonstrate that sustained attention abilities increase as one grows older because older individuals can develop compensatory strategies to pay attention ${ }^{8}$.

As for impulsivity, the analysis of Table 3 shows that the eight-year-old individuals were the ones with more alteration. Some articles ${ }^{34,36-38}$ verified that impulsivity diminishes as the person grows older. In this article, there was an exception for those seven years old. The literature reports that impulsivity is a key factor for differential diagnosis of attention-deficit/hyperactivity disorder ${ }^{8,36}$. Thus, the analyzes of impulsivity can help both characterize the children's auditory behavior and develop a differential diagnosis of children with suspicion for attention-deficit/hyperactivity disorder.
The SAAAT total score considers the sum of inattention with impulsivity scores. Hence, it was observed in Table 3, that the 11-year-old students have better performance when compared with the seven-year-old ones, proving that older individuals have a better performance when compared with the younger ones. However, in this study, the eight-yearold individuals presented the highest score when compared with the other age groups, especially those seven years old. This can be due to behavior, in which seven-year-old children are more inattentive, whereas the eight-year-old ones are more impulsive, causing an inferior performance in the test ${ }^{37}$.

When the performance in the test was compared among individuals according to breathing mode (Table 4), it was observed that there was a significant difference between breathing mode and SAAAT performance. The individuals from the ONB and MB groups presented inferior inattention, decreased vigilance and total error performance when compared with the NB group. According to the specialized literature, individuals from these groups are more susceptible to middle ear alterations, which leads to auditory deprivation. Consequently, acoustic patterns are more difficult to be formed, impairing attention, concentration, and auditory skills development - which are important for academic achievement. These alterations can justify the learning difficulties mouth-breathers have, due to the insufficient blood supply in these people's brain ${ }^{4}$.

The research's findings reinforce those from studies with SAAAT in a population with cleft lip and palate, in which it was demonstrated that individuals with middle ear deformations and a long stage of sensory deprivation can have CAP alteration, which in turn can be the cause of reduced auditory attention ability ${ }^{37,38}$.

Furthermore, studies demonstrate that mouthbreathers have inferior CAP ability performance when compared with nasal-breathers. This is due to alterations in the hematological system, which interfere with attention, reasoning, mood and general health ${ }^{7}$.

Therefore, sustained attention and vigilance are some of the processes that characterize attention and they are crucial to developing some essential abilities that lead to reading, writing and CAP development ${ }^{7,8,34,36}$.

Based on the results obtained, it is suggested that further studies be conducted with the SAAAT to assess and monitor sustained attention after therapeutic intervention.

It is believed that this study had great importance to confirm that alterations in breathing mode interfere 
with auditory abilities performance and, based on the findings, contribute to the rehabilitation process of these children.

\section{CONCLUSION}

Based on the data analysis, it was concluded that age and breathing mode influenced auditory behavior. Younger children and those presented with alteration in their breathing mode tend to present inattention and decreased vigilance. The individuals from the ONB and $M B$ groups presented an inferior performance in the SAAAT, as compared to that of the NB individuals, in the three types of error: inattention, decreased vigilance, and total errors, with significant differences in inattention and total errors.

\section{REFERENCES}

1. Saitoh I, Inada E, Kaihara Y, Nogami Y, Murakami D, Kubota $\mathrm{N}$ et al. An exploratory study of the factors related to mouth breathing syndrome in primary school children. Arch Oral Biol. 2018;92(8):57-61.

2. Fraga WS, Seixas VM, Santos JC, Paranhos LR, César CP. Mouth breathing in children and its impact in dental malocclusion: a systematic review of observational studies. Minerva Stomatol. 2018;67(3):129-38.

3. Pacheco AB, Silva AMT, Mezzomo CL, Berwig LC, Neu AP. Relação da respiração oral e hábitos de sucção não - nutritiva com alterações do sistema estomatognático. Rev. CEFAC. 2011;14(2):281-9.

4. Bianchini AP, Guedes ZCF, Hitos S. Respiração oral: causa $x$ audição. Rev. CEFAC. 2009;11(1):38-43.

5. Pinto JA, Gody LBM, Ribeiro RC, Mizoguchi El, Hirsch LAM, Gomes LM. Accuracy of peripheral arterial tonometry in the diagnosis of obstructive sleep apnea. Braz J Otorhinolaryngol. 2015;81(5):473-8.

6. Costa CMF. Influência do tratamento da respiração oral na sintomatologia de crianças com transtorno do déficit de atenção/hiperatividade [dissertação]. São Paulo (SP): Faculdade de Medicina da Universidade Federal de São Paulo; 2007.

7. Correa BM, Rossi AG, Roggia B, Silva AMT. Análise das habilidades auditivas de crianças com respiração oral. Rev. CEFAC. 2011;13(4):558-75.

8. Feniman MR, Lemos ICC. A habilidade de atenção auditiva sustentada em crianças. Braz J Otorhinolaryngol. 2007;25(4):280-4.
9. Lloyd LL, Kaplan H. Audiometric interpretation: a manual of basic audiometry. 2 th ed. Baltimore: University Park Press; 1978.

10. Jerger J. Clinical experience with impedance audiometry. Arch Otolaryngol. 1970;92(4):311-24.

11. Gelfand SA. The contralateral acoustic reflex threshold. In: Silman S (ed). The acoustic reflex: basic principles and clinical aplications. Orlando: Academic Press; 1984. p.137-86.

12. Jerger $S$, Jerger J. Alterações auditivas: um manual para avaliação clínica. São Paulo: Atheneu; 1989.

13. Altmann EBC, Khoury RBF, Ramos ALNF. Avaliação fonoaudiológica. In: Altmann EBC (ed). Fissuras labiopalatinas. 4a ed. Carapicuiba: Pró-fono; 1997. p. 325-65.

14. Nunes CL, Pereira LD, Carvalho GS. Scale of auditory behaviors and auditory behavior tests for auditory processing assessment in portuguese children. CoDAS. 2013;25(3):209-15.

15. Menezes VA, Leal RB, Pessoa RSP, Pontes RMES. Prevalência e fatores associados à respiração oral em escolares participantes do projeto Santo Amaro-Recife, 2005. Braz J Otorhinolaryngol. 2006;72(3):394-9.

16. Costa M, Valentim AF, Becker HMG, Motta AR. Findings of multiprofissional evaluation of mouth breathing children. Rev. CEFAC. 2015;17(3):864-78.

17. Cunha RA, Cunha DA, Bezerra LA, Melo ACC, Peixoto DM, Tashiro $T$ et al. Nasal aeration and respiratory muscle strength in mouth breathers' children. Rev. CEFAC. 2015;17(1):58-65.

18. Fridlin SL, Pereira LD, Perez AP. Relationship between data collected during the interview and auditory processing disorder. Rev. CEFAC. 2014;16(2):405-12.

19. Fensterseifer GS, Carpes O, Wechx LLM, Martha VF. Mouth breathing in children with learning disorders. Braz J Otorhinolaryngol. 2013;79(5):620-4.

20. Petry C, Pereira MU, Pitrez PMC, Jones MH, Stein RT. The prevalence of symptoms of sleepdisordered breathing in Brazilian schoolchildren. $J$ Pediatr. 2008;84(2):123-9.

21. Felcar JM, Bueno IR, Massan ACS, Torezan RP, Cardoso JR. Prevalence of mouth breathing in children form an elementar school. Ciênc. saúde colet. 2017;15(2):437-44.

22. Perilo TVC, Freitas CS, Cardoso NC, Motta AR, Alves LM. Habilidades cognitivo - linguísticas e sua relação com características respiratórias. Rev. CEFAC. 2012;15(3):579-91. 
23. Simon LF, Rossi AG. Triagem do processamento auditivo em escolares de 8 a 10 anos. Psicol Esc Educ. 2017;9(1):58-65.

24. Rhodes SK, Shimoda KC, Waid LR, O'Neil PM, Oexmann MJ, Collop NA et al. Neurocognitive deficits in morbidly obese children with obstructive slpeep apnea. J Pediatr. 1995;127(5):741-4.

25. Blunden S, Lushington A, Kennedy D, Martin J, Dawson D. Behavior and neurocognitive "perfomance" in children aged 5-10 years who snore compared to controls. J Clin Exper Neuropsy. 2000;22(5):554-68.

26. Kennedy J, Blunden S, Hirte C, Parsons DW, Martin AJ, Crowe E et al. Reduced neurocognition in children who snore. Pediatric Pulmonology. 2004;37(4):330-7.

27. Padilha FYOMM, Pinheiro MMC. Study on the application of the time-compressed speech in children. CoDAS. 2017;29(5):1-7.

28. Leite Filho CA, Silva FFD, Pradella-Hallinan M, Xavier SD, Miranda MC, Pereira LD. Auditory behavior and auditory temporal resolution in children with sleep-disordered breathing. Sleep Medicine. 2017;34(8):90-5.

29. Carvalho NG, Ubiali T, Amaral MIRD, Santos MFC. Procedures for central auditory processing screening in schoolchildren. Braz $\mathrm{J}$ Otorhinolaryngol. 2018;85(3):1-10.

30. Barry JG, Tomlin D, Moore DR, Dillon H. Use of Questionnaire-Based Measures in the assessment of listening difficulties in school-aged children. Ear Hear. 2015;36(6):300-13.

31. Yathiraj A, Maggu AR. Validation of the Screening Test for Auditory Processing (STAP) on school-aged children. Int $\mathrm{J}$ Pediatr Otorhinolaryngol. 2014;78(3):479-88.

32. Santos TS, Mancini PC, Sancio LP, Castro AR, Labanca L, Resende LM. Findings in behavioral and electrophysiological assessment of auditory processing. Audiol Commun Res. 2015;20(3):225-32.

33. Leles PM, Pacheco SST, Castro MP, Reis ACMB, Mathias EL, Coelho LMF et al. The relationship between the lack of stapedial muscle reflex and the presence of (central) auditory processing disorders. Rev. CEFAC. 2013;16(2):438-45.

34. Feminam MR, Rissatto ACS, Lauris JRP, Mondelli MFCG. Applicability of the free field Sustained Auditory Attention Ability Test (SAAAT). Int Arch Otorhinolaryngol. 2012;16(2):269-77.
35. Associação Brasileira de Audiologia. Fórum: diagnóstico audiológico - 2016. 31ㅇ Encontro Internacional de Audiologia. São Paulo. 2016.

36. Feniman MR, Ortelan RR, Lauris JRP, Campos CF, Cruz MS. Proposta de instrumento comportamental para avaliar a atenção auditiva sustentada. Rev Bras Otorrinolaringol. 2007;73(4):523-37.

37. Moraes TFD, Maximino LP, Feniman MR. A habilidade de atenção auditiva sustentada em crianças com fissura labiopalatina e transtorno fonológico. Rev Soc Bras Fonoaudiol. 2011;16(4):436-40.

38. Lemos ICC, Feniman MR. Teste de Habilidade de Atenção Auditiva Sustentada (THAAS) em crianças de sete anos com fissura labiopalatina. Braz J Otorhinolaryngol. 2010;76(2):199-205. 